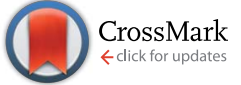

Cite this: J. Mater. Chem. A, 2016, 4, 2286

Received 10th November 2015

Accepted 8th January 2016

DOI: $10.1039 / c 5 t a 09073 c$

www.rsc.org/MaterialsA

\section{Nitrogen-enriched, ordered mesoporous carbons for potential electrochemical energy storage $\uparrow$}

\author{
Jinhui Zhu, ${ }^{a}$ Jun Yang, ${ }^{\text {*a }}$ Rongrong Miao, ${ }^{a}$ Zhaoquan Yao, ${ }^{b}$ Xiaodong Zhuang*b \\ and Xinliang Feng ${ }^{c}$
}

Nitrogen-doped ( $\mathrm{N}$-doped) porous carbons have drawn increasing attention due to their high activity for electrochemical catalysis, and high capacity for lithium-ion ( $\mathrm{Li}$-ion) batteries and supercapacitors. So far, the controlled synthesis of $\mathrm{N}$-enriched ordered mesoporous carbons (N-OMCs) for Li-ion batteries is rarely reported due to the lack of a reliable nitrogen-doping protocol that maintains the ordered mesoporous structure. In order to realize this, in this work, ordered mesoporous carbons with controllable $\mathrm{N}$ contents were successfully prepared by using melamine, F127 and phenolic resin as the $\mathrm{N}$-source, template and carbon-source respectively via a solvent-free ball-milling method. The asprepared N-OMCs which showed a high $\mathrm{N}$ content up to $31.7 \mathrm{wt} \%$ were used as anodes for Li-ion batteries. Remarkably, the N-OMCs with an N content of 24.4 wt\% exhibit the highest reversible capacity (506 mA h g ${ }^{-1}$ ) even after 300 cycles at $300 \mathrm{~mA} \mathrm{~g}^{-1}$ and a capacity retention of $103.3 \%$. N-OMCs were also used as electrode materials in supercapacitors and a capacity of $150 \mathrm{~F} \mathrm{~g}^{-1}$ at $0.2 \mathrm{~A} \mathrm{~g}^{-1}$ with stable cycling up to 2500 times at $1 \mathrm{~A} \mathrm{~g}^{-1}$ was achieved. These attractive results encourage the design and synthesis of high heteroatom content ordered porous carbons for applications in the field of energy storage and conversion.

\section{Introduction}

Shortage of fossil fuels forces researchers from both academia and industry to develop sustainable clean energy devices. In order to achieve this aim, a great deal of research effort has been directed towards lithium ion batteries (LIBs) and supercapacitors due to their long cycle life, high energy density and low toxicity. ${ }^{1-5}$ Among the numerous electrode materials for LIBs and supercapacitors, porous carbon materials, ${ }^{6-13}$ especially ordered mesoporous carbons (OMCs), ${ }^{14-18}$ have attracted tremendous attention owing to their unique structures, such as ordered mesoporous structure, high surface area and large pore volume. Two strategies have been developed to synthesize OMCs: the hard template (e.g., SBA-15 (ref. 19-22)) method and the soft template (e.g., Pluronic F127 (ref. 17 and 23-25)) method. Although the hard template method is one good pore

\footnotetext{
${ }^{a}$ Shanghai Electrochemical Energy Devices Research Center, School of Chemistry and Chemical Engineering, Shanghai Jiao Tong University, Shanghai 200240, P. R. China.E-mail: yangj723@sjtu.edu.cn

${ }^{b}$ Shanghai Key Lab of Electrical Insulation, Thermal Ageing \& Shanghai Electrochemical Energy Devices Research Center, School of Chemistry and Chemical Engineering, Shanghai Jiao Tong University, Shanghai 200240, P. R. China. E-mail: zhuang@sjtu.edu.cn

${ }^{c}$ Center for Advancing Electronics Dresden (cfaed), Department of Chemistry and Food Chemistry, Technische Universität Dresden, 01062 Dresden, Germany

$\dagger$ Electronic supplementary information (ESI) available. See DOI: $10.1039 / \mathrm{c} 5 \mathrm{ta} 09073 \mathrm{c}$
}

replicating way to porous carbons, it is time-consuming, costly and environmentally harmful due to the usage of aqueous $\mathrm{HF}$ as the etching agent. ${ }^{\mathbf{1 4}, 19}$ The soft template method has become one optimal choice since the solvent-free route to OMCs avoids organic solvents. ${ }^{26}$ OMCs based on the soft template method have been developed to gain enhanced lithium storage performance, such as reversible capacity and initial coulombic efficiency. ${ }^{15}$

In the past decade, heteroatom-doped (such as boron, ${ }^{27-29}$ nitrogen, ${ }^{29-35}$ phosphorous, ${ }^{29,36}$ and sulfur ${ }^{37}$ ) porous carbons have been proposed as active materials for electrochemical catalyzed oxygen reduction reaction, ${ }^{29,36,37}$ supercapacitors, ${ }^{27,28,31,32,35,38}$ dyesensitized solar cells, ${ }^{33} \mathrm{CO}_{2}$ capture $^{34,35}$ and batteries. ${ }^{30,37}$ Among these materials, nitrogen-doped ( $\mathrm{N}$-doped) porous carbons are the most favourable candidates for LIBs due to the larger electronegativity for nitrogen (i.e., 3.5) than that for carbon (i.e., 3.0), which may result in stronger interactions between $\mathrm{N}$-doped carbon and lithium ions and thereby facilitate lithium ion insertion..$^{7,13}$ Mao et al. ${ }^{13}$ and Zheng et al. ${ }^{7}$ have proved that a high $\mathrm{N}$ content of porous carbons usually improves lithium storage performance. However, the synthesis of rich N-doped OMCs by the conventional soft template method (the evaporation-induced self-assembly (EISA) technique ${ }^{35,39}$ or hydrothermal procedure ${ }^{40}$ ) is unapproachable due to the limited solubility of the $\mathrm{N}$-source in the organic solvent. Thereby, the synthesis of N-doped OMCs with a reliable controlling protocol for controlled $\mathrm{N}$ content with undestroyed ordered porous structures is desperate. 
Herein, we report a green chemical ball-milling strategy to synthesize N-enriched ordered mesoporous carbons (N-OMCs) by using melamine, F127 and phenolic resin as the N-source, template and carbon-source, respectively. The $\mathrm{N}$ contents of $\mathrm{N}-\mathrm{OMCs}$ can be controlled to be $6.3 \mathrm{wt} \%, 12.8 \mathrm{wt} \%, 19.9 \mathrm{wt} \%$, $24.4 \mathrm{wt} \%$ and $31.7 \mathrm{wt} \%$. The excellent hexagonal mesoporous structure and uniform nitrogen distribution of N-OMCs have been revealed by transmission electron microscopy (TEM), nitrogen physisorption, X-ray diffraction (XRD) patterns and others. Remarkably, the N-OMCs based LIBs exhibited N content relied performance under the premise of maintaining the pore structure (N\%: 6.3-24.4 wt\%). Besides, the N-OMCs based LIBs exhibited the highest initial coulombic efficiency up to $66.2 \%$, reversible capacity up to $506 \mathrm{~mA} \mathrm{~h} \mathrm{~g}^{-1}$ and coulombic efficiency of $99.5 \%$ with a current density of $300 \mathrm{~mA} \mathrm{~g}^{-1}$ for 300 cycles.

\section{Experimental section}

All of the reagents were purchased from Aldrich and Titan and used without further purification.

\section{Synthesis of nitrogen-enriched ordered mesoporous carbons (N-OMCs)}

N-OMCs were prepared by a green chemical ball-milling method. Typically, resorcinol (0.44 g, $4.0 \mathrm{mmol})$, terephthalaldehyde (0.56 g, $4.0 \mathrm{mmol})$, Pluronic F127 $\left(1.50 \mathrm{~g}, M_{\mathrm{w}}=\right.$ 12600 ) and melamine ( $X \mathrm{~g}, X=1,2,3,4$, and 5) were mixed and followed by ball-milling at a rotation speed of $200 \mathrm{rpm}$ for 15 min. The obtained colloidal samples were placed in a corundum boat and allowed to age at $80{ }^{\circ} \mathrm{C}$ for $5 \mathrm{~h}$ and $100{ }^{\circ} \mathrm{C}$ for another $5 \mathrm{~h}$. The obtained hard pinky solids were melamine blended ordered mesoporous polymers (Melamine-OMP- $X, X=$ 1, 2, 3, 4, and 5). Then, Melamine-OMPs were pyrolyzed at $600{ }^{\circ} \mathrm{C}$ under an inert atmosphere for $3 \mathrm{~h}$. After grinding, $\mathrm{N}$-enriched ordered mesoporous carbons (N-OMC- $X, X=1,2,3$, 4 , and 5) were produced. The ordered mesoporous polymer and carbon (OMP and OMC) were synthesized as the control sample by using the same procedure without using melamine. For proof-of-concept, N-OMC-4 was pyrolyzed at $900{ }^{\circ} \mathrm{C}$ in a nitrogen atmosphere for $2 \mathrm{~h}$ and in an ammonia atmosphere for $15 \mathrm{~min}$. The as-produced $\mathrm{N}$-doped porous carbon was denoted as N-OMC-4-900.

\section{Characterization}

The powder X-ray diffraction (XRD) patterns were recorded on an X-ray diffractometer (D/max-2200/PC, Rigaku) using $\mathrm{Cu}-\mathrm{K} \alpha$ radiation $(\lambda=0.15418 \mathrm{~nm})$ at $40 \mathrm{kV}$. Fourier transform infrared (FTIR) spectra were collected on a Paragon 1000 spectrophotometer (Perkin-Elmer, Inc., USA). Raman spectra were measured by using a Thermo Scientific DXR Raman microscope with a laser wavelength of $532 \mathrm{~nm}$ at room temperature. Thermogravimetric analysis (TGA) was conducted on a TGA TA 2050 thermal analyser system, the temperature increased from $50{ }^{\circ} \mathrm{C}$ to $900{ }^{\circ} \mathrm{C}$ with $10{ }^{\circ} \mathrm{C} \mathrm{min}{ }^{-1}$ in the flow of nitrogen at a flow rate of $30 \mathrm{~mL} \mathrm{~min}{ }^{-1}$. The scanning electron microscopy (SEM) and the transmission electron microscopy (TEM) images were recorded on a field emission scanning electron microscope (FESEM, JEOL JSM-7401F) and a transmission electron microscope (TEM, JOEL JEM-100CX), respectively. Nitrogen adsorption-desorption isotherms were obtained on an ASAP 2010 Accelerated Surface Area and Porosimetry System (Micromeritics Inc., USA) at $77 \mathrm{~K}$; all samples were degassed in a vacuum at $200{ }^{\circ} \mathrm{C}$ overnight prior to the measurements. The $\mathrm{X}$-ray photoelectron spectroscopy (XPS) spectra were acquired using a Kratos Axis UltraDLD spectrometer (Kratos Analytical-A Shimadzu Group Company) with a monochromatic Al-K $\alpha$ source (1486.6 eV). Elemental analysis (EA) was carried out using a Vario-EL Cube (Elementar) elemental analyser.

\section{Electrochemical measurements}

Lithium storage performances of the samples were evaluated using 2016 coin-type cells with lithium metal as the counter and reference electrodes at room temperature. The working electrodes were prepared by using a slurry coating procedure. Typically, the as prepared OMC or N-OMCs (80 wt\%), Super P (10 wt $\%$ ) and polyvinylidene fluoride (PVDF) (10 wt\%) were dispersed in $N$-methyl pyrrolidinone (NMP) $(0.625 \mathrm{~mL})$ and stirred for $12 \mathrm{~h}$, spread over a copper foil and vacuum dried at $80{ }^{\circ} \mathrm{C}$ for $6 \mathrm{~h}$. Finally, the work electrodes were obtained by punching the copper foil to $\Phi 12 \mathrm{~mm}$ sheets and further dried at $80{ }^{\circ} \mathrm{C}$ for $4 \mathrm{~h}$. Test cells were assembled in an argon-filled glove box, ENTEK ET20-26 as the separator and the electrolyte was $1 \mathrm{~mol} \mathrm{~L}^{-1} \mathrm{LiPF}_{6}$ in a mixture of ethylene carbonate (EC) and dimethyl carbonate (DMC) (1:1 in volume ratio). All the cells were charged and discharged on a LAND battery test system (Wuhan Kingnuo Electronics Co., Ltd., China) at room temperature with the current densities of $100 \mathrm{~mA} \mathrm{~g}^{-1}$ for the initial two cycles and $300 \mathrm{~mA} \mathrm{~g}^{-1}$ for the consequent cycles. The cut-off voltage was $0.01 \mathrm{~V}$ to $3.0 \mathrm{~V}$ versus $\mathrm{Li} / \mathrm{Li}^{+}$. Cyclic voltammetry (CV) was measured on a CHI640D electrochemical station between 0.01 and $3.0 \mathrm{~V}$ with a scan rate of $0.1 \mathrm{mV} \mathrm{s}^{-1}$. Electrochemical impedance spectroscopy (EIS) measurements were performed on an AutoLAB 302N Impedance Analyser in the frequency range of $100 \mathrm{KHz}$ to $0.01 \mathrm{~Hz}$. The supercapacitor electrode was prepared by mixing N-OMC-4-900 (80 wt\%), Super $\mathrm{P}$ (10 wt\%) and polytetrafluoroethylene (PTFE) (10 wt\%) in deionized water, spreading the obtained slurry on Ni foam, and finally drying at $60{ }^{\circ} \mathrm{C}$ in a vacuum for $6 \mathrm{~h}$. It should be mentioned that a lower content of PTFE binder, such as conventional $5 \mathrm{wt} \%$, cannot ensure the integrity of the electrode. The capacitive performance of the as-prepared electrode was evaluated using a conventional three-electrode system equipped with an $\mathrm{Ag} / \mathrm{AgCl}$ reference electrode, a platinum counter electrode and a $6 \mathrm{M} \mathrm{KOH}$ solution electrolyte.

\section{Results and discussion}

\section{Material characterization}

$\mathrm{N}$-enriched ordered mesoporous carbons (N-OMCs) were prepared by a green chemical ball-milling method (Scheme 1). Resorcinol and terephthalaldehyde, melamine and block copolymers Pluronic F-127 were used as the carbon source, N 


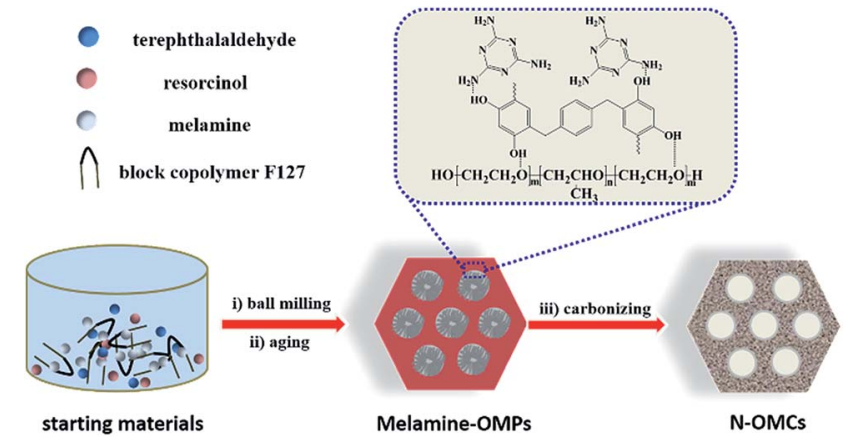

Scheme 1 Synthesis procedure for N-OMCs. (i) Resorcinol, terephthalaldehyde, Pluronic F127 and melamine, ball milling at 200 rpm, 15 min; (ii) $80^{\circ} \mathrm{C}$ for $5 \mathrm{~h}$, then $100{ }^{\circ} \mathrm{C}$ for $5 \mathrm{~h}$; (iii) $\mathrm{Ar}, 600^{\circ} \mathrm{C}, 3 \mathrm{~h}$.

source and soft template, respectively. After one step of the ballmilling process for $15 \mathrm{~min}$, the as-produced jelly was further treated under 80 and $100^{\circ} \mathrm{C}$ for total $10 \mathrm{~h}$ before pyrolysis under $600{ }^{\circ} \mathrm{C}$ for $3 \mathrm{~h}$. This green chemical method for the preparation of ordered mesoporous carbons not only successfully realizes the $\mathrm{N}$ doping but also can scale up the preparation of N-OMCs without any by-products.

In order to study the structure properties of MelamineOMPs, Fourier transform infrared (FTIR) spectroscopy, X-ray photoelectron spectroscopy (XPS), small angle X-ray diffraction (XRD) and thermogravimetric analysis (TGA) were carried out. Due to the similarity, Melamine-OMP-4 was discussed as the representative example hereafter if not stated. From the FTIR spectra in Fig. 1a, the transmittance peak at $1554 \mathrm{~cm}^{-1}$ for Melamine-OMP-4 can be attributed to the stretching vibration of the $\mathrm{C}=\mathrm{N}$ bond which indicates the successfully introduction of melamine into the ordered porous polymer structure. ${ }^{39}$ Two peaks (403.5 and $396.8 \mathrm{eV}$ ) can be observed from the N 1s XPS spectrum of Melamine-OMP-4 in Fig. 1b, which correspond to amino $\mathrm{N}$ and 1,3,5-triazine $\mathrm{N}$, suggesting the existence of melamine in Melamine-OMP-4. Two intense peaks located at
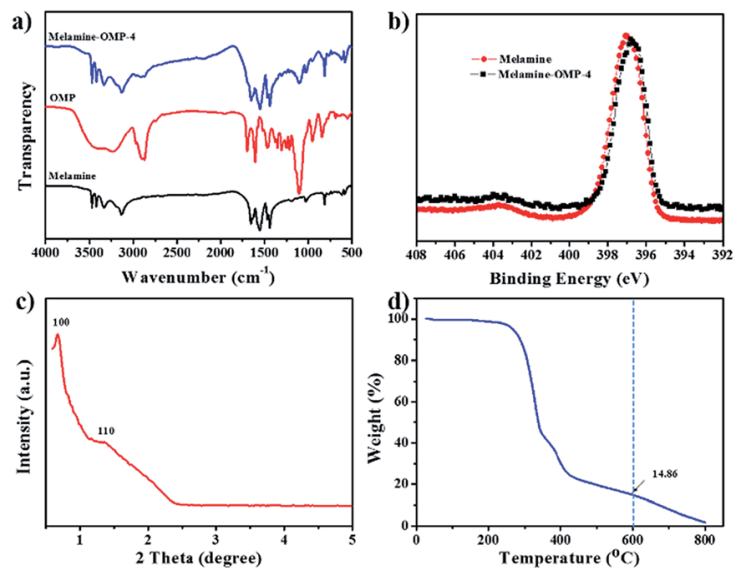

Fig. 1 Structure analysis for Melamine-OMP-4. (a) FTIR spectra of Melamine-OMP-4, melamine and OMP; (b) N 1s XPS spectra of melamine and Melamine-OMP-4; (c) small angle XRD pattern and (d) TGA curve of Melamine-OMP-4. a $2 \theta$ value of $0.68^{\circ}$ and $1.36^{\circ}$ can be easily found in small angle XRD patterns (Fig. 1c), which are indexed to (100) and (110) of a two-dimensional (2D) hexagonal mesoporous structure $(p 6 m) .{ }^{23}$ All these results indicate the successful preparation of the melamine blended ordered mesoporous structure for Melamine-OMPs. Based on the TGA curve of Melamine-OMP-4, two distinct weight losses located between $250-350^{\circ} \mathrm{C}$ and $350-$ $400{ }^{\circ} \mathrm{C}$ can be ascribed to the partial sublimation of melamine and the decomposition of F127, respectively (Fig. 1d)..$^{39,41}$ Upon increasing to $600{ }^{\circ} \mathrm{C}, 14.9 \%$ weight is maintained, suggesting the possible carbon-precursor nature of Melamine-OMPs.

To gain insight into N-OMCs, elemental analysis, XRD patterns and Raman spectra were employed. The nitrogen content (wt\%) analysis for the as-prepared N-OMCs is illustrated in Fig. 2a. It is noticeable that the nitrogen content of N-OMC-5 reaches $31.7 \mathrm{wt} \%$, which is much higher than the reported value. ${ }^{35,42}$ In addition, the nitrogen contents for N-OMCs increase along with the increase in the amount of starting melamine in the preparation procedure. Therefore, it is a reliable way to prepare $\mathrm{N}$-doped porous carbons with controllable $\mathrm{N}$ contents. According to the small angle XRD of N-OMCs in Fig. 2b, all of the samples show two distinct peaks which can be indexed to (100) and (110) of 2D hexagonal mesostructures $(\mathrm{p} 6 \mathrm{~m}) \cdot{ }^{43}$ With the increase of nitrogen content from $\mathrm{N}-\mathrm{OMC}-1$ to N-OMC-5, the intensity of the diffraction peaks reduces significantly. This result indicates that the decline of ordering degree of the mesostructures due to the increased melamine breaks the continuity of the ordered structures. The calculated unit cell parameters of OMC and N-OMC- $X(X=1-5)$ were 11.0, 10.5, 11.8, 12.0, 12.7 and $12.3 \mathrm{~nm}$ (Table 1), respectively. The increased trend implies the expansion of mesostructures ${ }^{35}$ caused by dispersed melamine in resin frameworks that increased the distance of polymer chains. The wide angle XRD patterns of N-OMCs (Fig. 2c) exhibit one obvious broad characteristic peak around $22.36-23.68^{\circ}$ and another relatively weak peak around $43.62-43.80^{\circ}$ which can be ascribed to the graphite (002) and (101) interlayers. ${ }^{39,44}$ The $d$-spacing (002) of
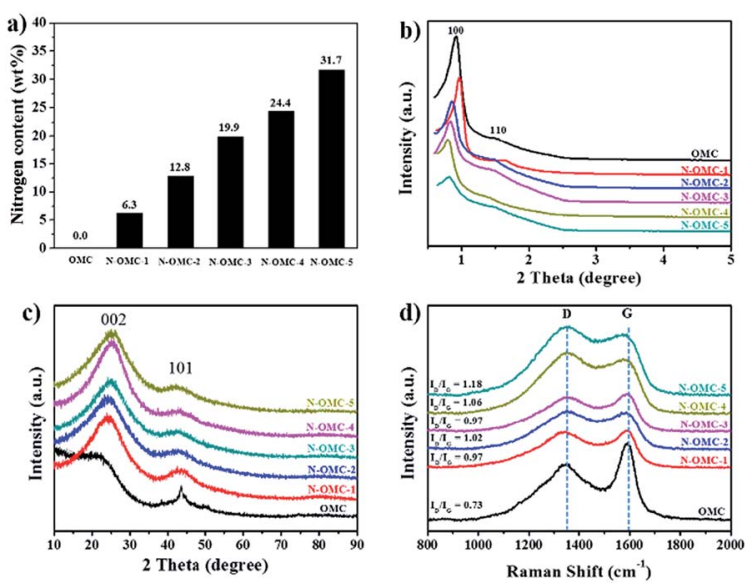

Fig. 2 Structure analysis of OMC and N-OMCs. (a) Nitrogen weight contents (wt\%) based on elemental analysis; (b) small angle and (c) wide angle XRD patterns; (d) Raman spectra. 
Table 1 Textural parameters of OMC and N-OMCs based on nitrogen physisorption and small angle XRD analysis ${ }^{a}$

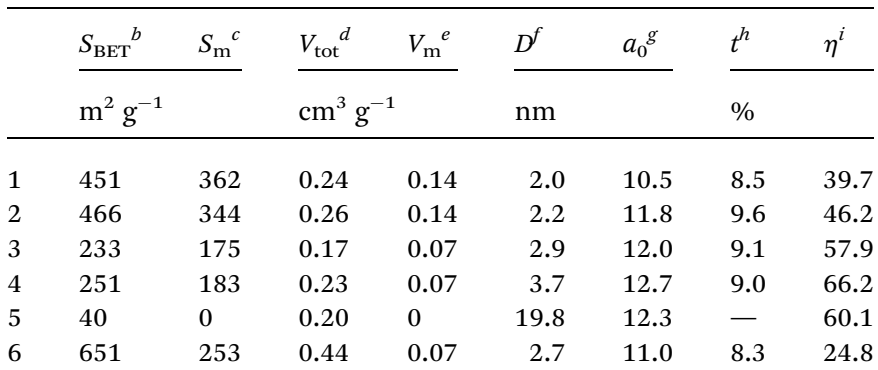

${ }^{a}$ Note: (sample 1-6: N-OMC-1, N-OMC-2, N-OMC-3, N-OMC-4, N-OMC5 , N-OMC). ${ }^{b}$ Surface area calculated by the BET method. ${ }^{c}$ Micropore area calculated by the $V-t$ method. ${ }^{d}$ Total pore volume at $p / p_{0}=$ 0.995. ${ }^{e}$ Micropore volume. ${ }^{f}$ Average pore size calculated by using the NL-DFT model. ${ }^{g}$ Unit cell parameter calculated on the basis of hexagonal unit cell: $a_{0}=2 d_{100} / 3^{1 / 2}$ and $d_{100}$ calculated from the Bragg law on the positions of the $2 \theta$ reflection lines: $d_{100}=\lambda / 2 \sin (2 \theta / 2)$. ${ }^{h}$ Pore wall thickness calculated from: $t=a_{0}-D .{ }^{i}$ Initial coulombic efficiency for LIBs.

the samples was $0.35-0.40 \mathrm{~nm}$ calculated by the Bragg law, which is little larger than that of graphite $(0.34 \mathrm{~nm})$. The (002) peak shifted to a larger angle with the increase of nitrogen content, which also indicates the reduction of the interlayer distance. In addition, the characterized peak of other nitrogen species (e.g., $\mathrm{C}_{3} \mathrm{~N}_{4}$ ) was not found in the XRD patterns. ${ }^{\mathbf{4 1 , 4 5}}$

Raman spectroscopy is an efficient diagnostic tool to observe the subtle structural variation of the carbon-based materials. The G-band with $E_{2 g}$ symmetry at around $1595 \mathrm{~cm}^{-1}$ is related to $\mathrm{sp}^{2}$ carbon and the $\mathrm{D}$-band with $\mathrm{A}_{1 \mathrm{~g}}$ symmetry at around $1310 \mathrm{~cm}^{-1}$ is assigned to atomic displacement, disordered carbon, edge defect and other defects $\left(\mathrm{sp}^{3}\right.$ carbon, dangling carbon and vacancies, etc. $)$. A ratio of $\mathrm{D}$ band to $\mathrm{G}$ band $\left(I_{\mathrm{D}} / I_{\mathrm{G}}\right)$ can reflect the degree of crystallinity of carbon materials. ${ }^{\mathbf{6 , 9 4 6}} \mathrm{An}$ obvious increase of $I_{\mathrm{D}} / I_{\mathrm{G}}$ can be observed with the enhanced nitrogen contents in N-OMCs (Fig. 2d), which indicates that more defects are generated with the increasing nitrogen content. Interestingly, the D band and G band for OMC and $\mathrm{N}$-OMCs are about 1350 and $1587 \mathrm{~cm}^{-1}$, respectively. These features make the as-prepared materials promising candidates for lithium ion battery anodes due to the high nitrogen content and well controlled ordered mesoporous structure.

The morphology and microstructure of the as-prepared samples were investigated by field emission scanning electron microscopy (SEM) and transmission electron microscopy (TEM). The SEM image and elemental mapping for N-OMC-4 are shown in Fig. 3a and b, respectively. N-OMC-4 exhibits irregularly polyhedral particles with the size range from hundreds of nanometers to ten micrometers. The elemental mapping illustrates the uniformly distributed nitrogen, carbon and oxygen in N-OMC-4. TEM images and the corresponding Fast Fourier Transformation (FFT) diffractograms of N-OMC-4 were also revealed. The ordered arrangement of mesopores with long-range periodicity over large domains viewed from (110) (Fig. 3c) and (001) (Fig. 3d) directions could be observed. All these results indicate the successful preparation of N-OMC-4 with $2 \mathrm{D}$ hexagonal mesostructures $(p 6 m)$. The TEM and FFT
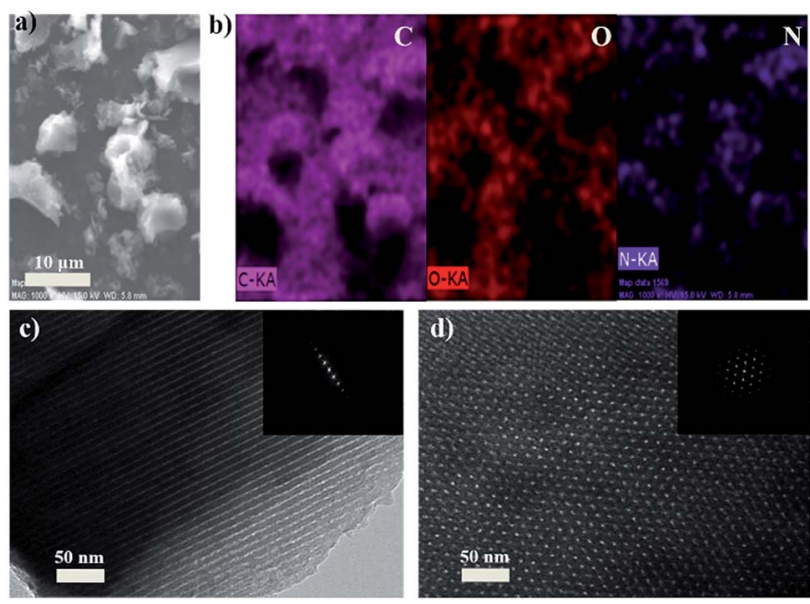

Fig. 3 Morphology and microstructures of N-OMC-4. SEM image (a) and elemental mapping (b); TEM images viewed along the [110] (c) and [001] (d). The insets are the corresponding fast Fourier transformation (FFT) diffractograms.

images of other samples are illustrated in Fig. S1.† All of the samples exhibit similar well-ordered 2D hexagonal mesostructures $(p 6 m)$ in large domains.

The chemical nature of N-OMCs was further investigated by XPS. Only two peaks at about $285 \mathrm{eV}$ and $533 \mathrm{eV}$, which are ascribed to $\mathrm{C}$ and $\mathrm{O}$, respectively, can be detected from OMC for the XPS survey spectrum (Fig. 4a). Three peaks at about $285 \mathrm{eV}$, $400 \mathrm{eV}$ and $533 \mathrm{eV}$ which attribute to $\mathrm{C}, \mathrm{N}$ and $\mathrm{O}$ are detected from N-OMCs. All of $\mathrm{N} 1$ s XPS spectra of N-OMC- $X(X=2-5)$ (Fig. 4b) can be deconvoluted into three peaks at 398.2, 398.8 and $400.4 \mathrm{eV}$ which are ascribed to 1,3,5-triazine $\mathrm{N}$, pyridinic $\mathrm{N}$ and pyrrolic $\mathrm{N}$, respectively. ${ }^{31,39,43}$ Unlike $\mathrm{N}-\mathrm{OMC}-X(X=2-5)$, $\mathrm{N}$-OMC-1 exhibits graphite-like $\mathrm{N}$ and no 1,3,5-triazine $\mathrm{N}$. The graphite-like $\mathrm{N}$ bonded with three $\mathrm{sp}^{2}$ carbons was mostly located inside the graphite carbon plane that will lead to the shift of $\mathrm{D}$ band in the Raman spectrum, while the presence of pyridinic $\mathrm{N}$ and pyrrolic $\mathrm{N}$ will broaden the Raman peak. ${ }^{13}$ These results are consistent with the Raman spectra. The contents of varied nitrogen species for each sample are listed in Table S1. $\dagger$
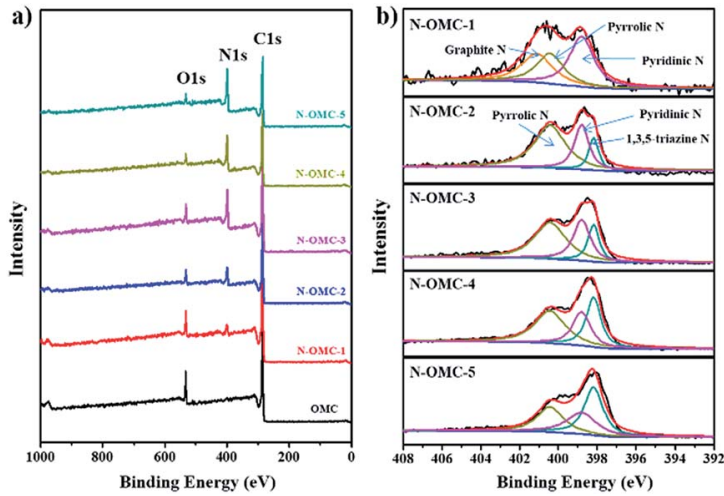

Fig. 4 XPS spectra of OMC and N-OMCs (a) and their corresponding $\mathrm{N}$ 1s XPS spectra (b). 
The porous nature of OMC and N-OMCs is confirmed from nitrogen physisorption measurements. The nitrogen adsorption-desorption isotherms for OMC and N-OMCs are illustrated in Fig. 5. All of the as-prepared materials exhibit typical type-IV curves with small $\mathrm{H} 2$ hysteresis loops, associated with the adsorption and desorption behaviour of cage-like mesoporous structures. $^{32,35,39}$ The distinct capillary condensation steps further confirm the mesoporous structures of the samples. OMC and N-OMCs also exhibit a very high absorbed volume at low relative pressure $\left(p / p_{0}\right)$, which indicates the characteristics of well-developed microporosity. ${ }^{33}$ The unclosed adsorption and desorption isotherms of the N-OMCs can be attributed to the strong interaction between $\mathrm{N}_{2}$ and $\mathrm{N}$-contained functional groups existing in the micropore surface of the materials. ${ }^{24}$ The pore size distributions of the as-prepared materials calculated by using the NL-DFT model are shown in the inset of their corresponding adsorption/desorption isotherms. N-OMC- $X(X=1-4)$ shows micropore and mesopore distribution while N-OMC-5 exhibits mesopore and little macropore distribution. According to this, the average pore sizes of N-OMC- $X(X=1-5)$ are about 2.0, 2.2, 2.9, 3.7 and $19.8 \mathrm{~nm}$, respectively. The nitrogen physisorption properties of OMC and N-OMCs are summarized in Table 1. The Brunauer-Emmett-Teller (BET) surface area, pore volume and pore size of OMC are $651 \mathrm{~m}^{2} \mathrm{~g}^{-1}, 0.44 \mathrm{~cm}^{3} \mathrm{~g}^{-1}$, and $2.7 \mathrm{~nm}$, respectively. With an increased nitrogen content in the samples from $6.3 \mathrm{wt} \%$ to $31.7 \mathrm{wt} \%$, the BET surface area, pore volume as well as the micropore volume decrease, which could be caused by the fact that a high content of melamine results in breaking of ordered mesopore structures.

\section{Lithium ion batteries testing}

To gain insight into the lithium storage performance of the asprepared materials, the electrodes of OMC and N-OMCs were prepared and compared. Especially, the electrochemical performance of N-OMC-4 is discussed as a representative example. Cyclic voltammograms of the N-OMC-4 electrode for
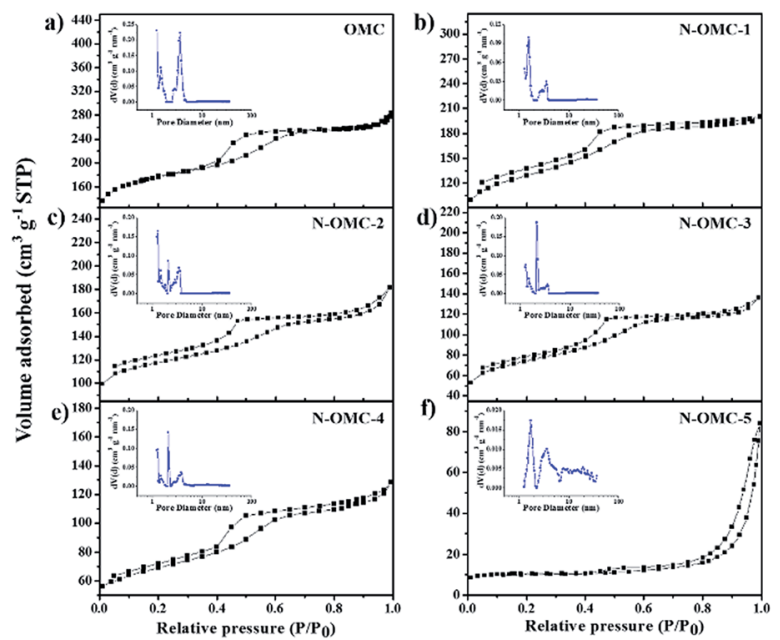

Fig. 5 Nitrogen adsorption-desorption isotherms and the corresponding pore size distribution (insert) for OMC and N-OMCs. the initial five cycles are recorded to survey the redox reactions with respect to the lithiation and delithiation processes (Fig. S2 $\uparrow$ ). The reduction peak appearing at about $0.5 \mathrm{~V}$ in the first CV cycle is attributed to the decomposition of the electrolyte and formation of the solid-electrolyte-interface (SEI) film., ${ }^{9,13}$ The disappearance of this peak in the subsequent cycles implies that the as-formed SEI film is considerably robust which can avoid the direct contact between the N-OMC-4 electrode and electrolyte, thereby enhancing the reversible capacity and coulombic efficiency. Another reduction peak at $\sim 0 \mathrm{~V}$ can be ascribed to lithium ion intercalation into the N-OMC-4 electrode. Accordingly, the broad shoulder oxidation peak at 0.1-0.5 $\mathrm{V}$ is attributed to the extraction of lithium ions from the N-OMC4 electrode, which also indicates an electrochemical doublelayer capacitor (EDLC) charge-discharge process. ${ }^{14,47}$ All of the reduction and oxidation peaks overlap very well after the second CV cycle, indicating the good reversibility and stability. The lithium storage properties of N-OMCs were further investigated by galvanostatic charge-discharge measurements (Fig. 6a and S3 $\dagger$ ). As shown in Fig. 6a, the initial two charge-discharge curves of N-OMC-4 at $100 \mathrm{~mA} \mathrm{~g}^{-1}$ exhibit a plateau at $c a .0 .8 \mathrm{~V}$ ( $v s . \mathrm{Li} / \mathrm{Li}^{+}$) which is primarily caused by the reaction of lithium with the electrolyte and followed by the formation of SEI films on the surface of N-OMC- $4 .{ }^{13}$ Similar to CV cycles, this plateau disappears after the first cycle, indicating that the formation of SEI films has been completed. The first discharge and charge capacity of the N-OMC-4 electrode are calculated to be 1034 and $684 \mathrm{~mA} \mathrm{~h} \mathrm{~g}{ }^{-1}$, respectively, corresponding to the initial coulombic efficiency of $66.2 \%$. After 10 cycles, the discharge and charge capacities of the N-OMC-4 electrode are stabilized at 451 and $448 \mathrm{~mA} \mathrm{~h} \mathrm{~g}{ }^{-1}$, and the coulombic efficiency reaches $99.3 \%$. The charge capacity increases to $506 \mathrm{~mA} \mathrm{~h} \mathrm{~g}^{-1}$ and the coulombic efficiency remains at $99.4 \%$ after 300 cycles. The comprehensive calculated results of N-OMCs are listed in Table 1. Fig. $6 \mathrm{~b}$ shows the galvanostatic cycling performance of $\mathrm{N}-\mathrm{OMCs}$ at $100 \mathrm{~mA} \mathrm{~g}^{-1}$ for the initial two cycles and $300 \mathrm{~mA} \mathrm{~g}^{-1}$
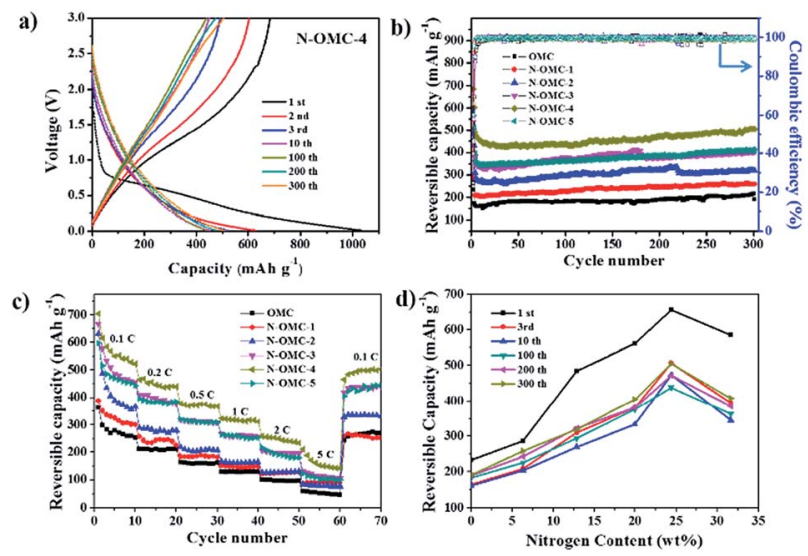

Fig. 6 Performance of LIBs based on N-OMCs anodes. (a) Typical discharge-charge curves; (b) cycle performances and coulombic efficiency; (c) rate capability $\left(1 \mathrm{C}=372 \mathrm{~mA} \mathrm{~g}^{-1}\right)$ and (d) the correlation between reversible capacities and nitrogen contents for $\mathrm{N}$-OMCs at different cycle numbers. 
from the $3^{\text {rd }}$ to $300^{\text {th }}$ cycles. All of the as-prepared samples exhibit excellent cyclability during the charge/discharge process. Their reversible capacities gradually increase after the 10 th cycle which is related to the meso- and micropore nature of $\mathrm{N}-\mathrm{OMCs}^{13}$ and the activating process of nitrogen-doped sites. ${ }^{6}$ The charge capacities of OMC and N-OMC- $X(X=1-5)$ at the 300th cycle are 191, 259, 319, 405, 506 and $408 \mathrm{~mA} \mathrm{~h} \mathrm{~g}{ }^{-1}$, respectively. N-OMC-4 exhibits the highest charge capacity which is comparable to the reported $\mathrm{N}$-doped carbon materials (listed in Table $\mathrm{S} 2 \dagger) .{ }^{\mathbf{9}, 46}$ The rate capabilities of N-OMCs are illustrated in Fig. 6c. N-OMC-4 exhibits a reversible capacity of $\sim 520 \mathrm{~mA} \mathrm{~h} \mathrm{~g}^{-1}$ at a current density of $0.1 \mathrm{C}\left(1 \mathrm{C}=372 \mathrm{~mA} \mathrm{~g}^{-1}\right)$ and $\sim 150 \mathrm{~mA} \mathrm{~h} \mathrm{~g}^{-1}$ at $5 \mathrm{C}$. Moreover, the reversible capacities of all the samples return to their original values when the current density turns back from $5 \mathrm{C}$ to $0.1 \mathrm{C}$, suggesting the good stability of the as-prepared materials. ${ }^{6}$

In order to understand the superior LIBs performance, the interfacial properties of OMC and N-OMCs are examined and compared. Nyquist plots of OMC and N-OMCs in Fig. S4 $\dagger$ exhibit two semicircles at high-medium frequency and low frequency. The first semicircle mainly represents the SEI resistance, while the second one represents the charge transfer resistance. ${ }^{\mathbf{6}, 9,16}$ According to the equivalent circuit (inset in Fig. S4 $\dagger)$, the electrolyte resistance $\left(R_{\mathrm{S}}\right)$, the SEI resistance $\left(R_{\mathrm{SEI}}\right)$ and the charge transfer resistance $\left(R_{\mathrm{ct}}\right)$ of OMC and N-OMCs are summarized in Table S3. $\dagger$ The $R_{\mathrm{SEI}}$ and $R_{\mathrm{ct}}$ of OMC are 240.1 and $173.9 \Omega$, respectively, which significantly decline after the introduction of nitrogen in N-OMCs. This result indicates that $\mathrm{N}$-doping is one promising method to improve the interfacial properties of porous carbons for LIBs and other energy-related applications.

In order to establish a reliable relationship between LIBs performance and nitrogen contents, the correlation between reversible capacity and nitrogen contents of N-OMCs at different cycles $\left(1^{\text {st }}, 3^{\text {rd }}, 10^{\text {th }}, 100^{\text {th }}, 200^{\text {th }}\right.$ and $\left.300^{\text {th }}\right)$ is shown in Fig. 6d. As illustrated, N-OMC-4 with a nitrogen content of 24.4 wt\% exhibits the largest capacity. Although high content nitrogen-doping is a promising method for improving the capacity of LIBs, the porous structure is also critical. The higher nitrogen content ( $31.7 \mathrm{wt} \%$ for N-OMC-5) is not beneficial to the electrode performance due to its poor porosity $\left(S_{\mathrm{BET}}=33 \mathrm{~m}^{2}\right.$ $\mathrm{g}^{-1}$ ). On the other hand, although the conductivity of OMCs can increase generally by enhancing the annealing temperature, it is found that the cycle capacity of the carbonized product from
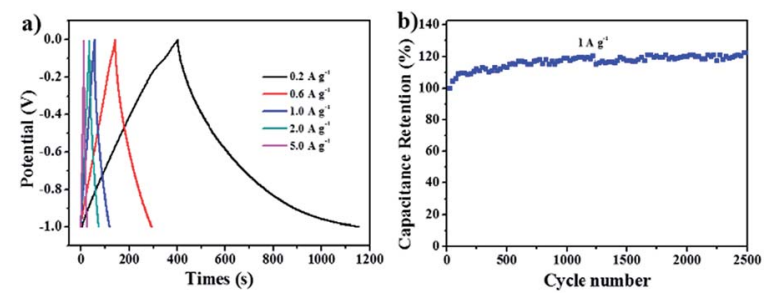

Fig. 7 Capacitive performance of the N-OMC-4-900 electrode: (a) galvanostatic charge-discharge curves at different current densities in $6 \mathrm{M} \mathrm{KOH}$; (b) cycle performance at $1.0 \mathrm{~A} \mathrm{~g}^{-1}$ for 2500 cycles.
Melamine-OMP-4 declined significantly with an increased temperature from $600{ }^{\circ} \mathrm{C}$ to $900{ }^{\circ} \mathrm{C}$ (See Fig. S5†). Actually, several factors, such as conductivity, nitrogen content and pore structure, contributed to the final electrode performance. Here the nitrogen content is much more important than other factors.

\section{Supercapacitor testing}

For proof-of-concept, N-OMC-4-900 (the pyrolysis product of N-OMC-4, see Experimental part) was further used as the electrode material in supercapacitors. The cycle voltammetry of N-OMC-4-900 in $6 \mathrm{M} \mathrm{KOH}$ media shows a nearly rectangular shape, suggesting the double-layer capacitance behaviour (Fig. S8a $\dagger$ ). The charge-discharge tests of N-OMC-4-900 are performed at current densities from 0.2 to $5.0 \mathrm{~A} \mathrm{~g}^{-1}$ (Fig. 7a) and the specific capacitance calculated from the charge-discharge curve is $150 \mathrm{~F} \mathrm{~g}^{-1}$ at $0.2 \mathrm{~A} \mathrm{~g}^{-1}$. As shown in Fig. 7b, a high cycling stability is achieved up to 2500 cycles at $1 \mathrm{~A} \mathrm{~g}^{-1}$. This promising electrochemical capacitance may be attributed to the high surface area $\left(513 \mathrm{~m}^{2} \mathrm{~g}^{-1}\right.$, Fig. S6 $\dagger$ and Table $\left.\mathrm{S} 4 \dagger\right)$, rich nitrogendoped active sites $(5.0 \mathrm{wt} \%$, Fig. S7 $\dagger$ ) and the high conductivity (Fig. S8b $\dagger$ ) of N-OMC-4-900.

\section{Conclusions}

Ordered mesoporous carbons with controllable nitrogen contents (N-OMCs) were synthesized by a solvent-free ballmilling method using melamine, F127 and phenolic resin as the $\mathrm{N}$-source, template and carbon-source, respectively. The highest nitrogen content of 31.7 wt\% was obtained with maintained ordered mesoporous structure. As an anode material for LIBs, $\mathrm{N}$-OMCs exhibit high reversible capacity and stable cycle performance. The N-OMC-4 with a nitrogen content of $24.4 \mathrm{wt} \%$ displays the initial coulombic efficiency as high as $66.2 \%$, and a reversible capacity of $506 \mathrm{~mA} \mathrm{~h} \mathrm{~g}^{-1}$ after 300 cycles at $300 \mathrm{~mA}$ $\mathrm{g}^{-1}$. Furthermore, it is found that the specific capacities of $\mathrm{N}$-OMCs are proportional to the $\mathrm{N}$ contents in a range of 6.3-24.4 wt\%. Together with the promising supercapacitor performance ( $150 \mathrm{~F} \mathrm{~g}^{-1}$ at $0.2 \mathrm{~A} \mathrm{~g}^{-1}$ ), the as-developed nitrogendoped ordered mesoporous carbon is promising for energy storage and conversion.

\section{Acknowledgements}

The authors thank the financial support from 973 Programs of China (2014CB932303), Natural Science Foundation of China (51403126) and SJTU-UM Joint Research Project.

\section{Notes and references}

1 E. Yoo, J. Kim, E. Hosono, H.-S. Zhou, T. Kudo and I. Honma, Nano Lett., 2008, 8, 2277.

2 H. Li, Z. Wang, L. Chen and X. Huang, Adv. Mater., 2009, 21, 4593.

3 J. B. Goodenough and Y. Kim, Chem. Mater., 2010, 22, 587. 
4 L. Ji, Z. Lin, M. Alcoutlabi and X. Zhang, Energy Environ. Sci., 2011, 4, 2682.

5 X. Zhuang, F. Zhang, D. Wu and X. Feng, Adv. Mater., 2014, 26, 3081.

6 X. Liu, Y. Wu, Z. Yang, F. Pan, X. Zhong, J. Wang, L. Gu and Y. Yu, J. Power Sources, 2015, 293, 799.

7 F. Zheng, Y. Yang and Q. Chen, Nat. Commun., 2014, 5, 5261.

8 Z. Jiang, Z.-J. Jiang, X. Tian and L. Luo, Electrochim. Acta, 2014, 146, 455.

9 W. Ren, D. Li, H. Liu, R. Mi, Y. Zhang, L. Dong and L. Dong, Electrochim. Acta, 2013, 105, 75.

10 P. F. Fulvio, G. M. Veith, J. L. Adcock, S. S. Brown, R. T. Mayes, X. Wang, S. M. Mahurin, B. Guo, X.-G. Sun, A. A. Puretzky, C. M. Rouleau, D. B. Geohegan and S. Dai, J. Mater. Chem. A, 2013, 1, 9414.

11 Y. Fang, Y. Lv, R. Che, H. Wu, X. Zhang, D. Gu, G. Zheng and D. Zhao, J. Am. Chem. Soc., 2013, 135, 1524.

12 L. Qie, W.-M. Chen, Z.-H. Wang, Q.-G. Shao, X. Li, L.-X. Yuan, X.-L. Hu, W.-X. Zhang and Y.-H. Huang, Adv. Mater., 2012, 24, 2047.

13 Y. Mao, H. Duan, B. Xu, L. Zhang, Y. Hu, C. Zhao, Z. Wang, L. Chen and Y. Yang, Energy Environ. Sci., 2012, 5, 7950.

$14 \mathrm{H}$. Zhou, S. Zhu, M. Hibino, I. Honma and M. Ichihara, Adv. Mater., 2003, 15, 2107.

15 H.-Q. Li, R.-L. Liu, D.-Y. Zhao and Y.-Y. Xia, Carbon, 2007, 45, 2628.

16 M.-S. Kim, D. Bhattacharjya, B. Fang, D.-S. Yang, T.-S. Bae and J.-S. Yu, Langmuir, 2013, 29, 6754.

17 A. F. Leonard, C. J. Gommes, M. L. Piedboeuf, J. P. Pirard and N. Job, Microporous Mesoporous Mater., 2014, 195, 92.

18 D. Saikia, T.-H. Wang, C.-J. Chou, J. Fang, L.-D. Tsai and H.-M. Kao, RSC Adv., 2015, 5, 42922.

19 R. Ryoo, S. H. Joo, M. Kruk and M. Jaroniec, Adv. Mater., 2001, 13, 677.

20 Y. Wang, B. Li, C. Zhang, H. Tao, S. Kang, S. Jiang and X. Li, J. Power Sources, 2012, 219, 89.

21 L. Shen, X. Zhang, E. Uchaker, C. Yuan and G. Cao, Adv. Energy Mater., 2012, 2, 691.

22 L. Zeng, C. Zheng, J. Xi, H. Fei and M. Wei, Carbon, 2013, 62, 382.

23 Y. Meng, D. Gu, F. Zhang, Y. Shi, H. Yang, Z. Li, C. Yu, B. Tu and D. Zhao, Angew. Chem., Int. Ed., 2005, 117, 7215.

24 Y. Meng, D. Gu, F. Zhang, Y. Shi, L. Cheng, D. Feng, Z. Wu, Z. Chen, Y. Wan, A. Stein and D. Zhao, Chem. Mater., 2006, 18, 4447.
25 L. Borchardt, M. Oschatz, M. Lohe, V. Presser, Y. Gogotsi and S. Kaskel, Carbon, 2012, 50, 3987.

26 Q. W. Wang, Y. J. Mu, W. L. Zhang, L. S. Zhong, Y. Meng and Y. H. Sun, RSC Adv., 2014, 4, 32113.

27 T. Kwon, H. Nishihara, H. Itoi, Q.-H. Yang and T. Kyotani, Langmuir, 2009, 25, 11961.

28 X. Zhai, Y. Song, J. Liu, P. Li, M. Zhong, C. Ma, H. Wang, Q. Guo and L. Zhi, J. Electrochem. Soc., 2012, 159, E177.

29 C. H. Choi, S. H. Park and S. I. Woo, ACS Nano, 2012, 6, 7084. 30 Y. Qu, Z. Zhang, X. Zhang, G. Ren, Y. Lai, Y. Liu and J. Li, Carbon, 2015, 84, 399.

31 X. Wang, C.-G. Liu, D. Neff, P. F. Fulvio, R. T. Mayes, A. Zhamu, Q. Fang, G. Chen, H. M. Meyer, B. Z. Jang and S. Dai, J. Mater. Chem. A, 2013, 1, 7920.

32 W. Kim, M. Y. Kang, J. B. Joo, N. D. Kim, I. K. Song, P. Kim, J. R. Yoon and J. Yi, J. Power Sources, 2010, 195, 2125.

33 M. Chen, L.-L. Shao, Y.-P. Liu, T.-Z. Ren and Z.-Y. Yuan, J. Power Sources, 2015, 283, 305.

34 Z. Wu, P. A. Webley and D. Zhao, J. Mater. Chem., 2012, 22, 11379.

35 J. Wei, D. Zhou, Z. Sun, Y. Deng, Y. Xia and D. Zhao, Adv. Funct. Mater., 2013, 23, 2322.

36 C. H. Choi, S. H. Park and S. I. Woo, J. Mater. Chem., 2012, 22, 12107.

37 G.-l. Zhuang, J.-Q. Bai, X.-Y. Tao, J.-M. Luo, X.-D. Wang, Y.-F. Gao, X. Zhong, X.-N. Li and J.-G. Wang, J. Mater. Chem. A, 2015, 3, 20244.

38 G. Lota, B. Grzyb, H. Machnikowska, J. Machnikowski and E. Frackowiak, Chem. Phys. Lett., 2005, 404, 53.

39 J. Yu, M. Guo, F. Muhammad, A. Wang, G. Yu, H. Ma and G. Zhu, Microporous Mesoporous Mater., 2014, 190, 117.

40 G.-P. Hao, W.-C. Li, S. Wang, G.-H. Wang, L. Qi and A.-H. Lu, Carbon, 2011, 49, 3762.

41 S. C. Yan, Z. S. Li and Z. G. Zou, Langmuir, 2009, 25, 10397. 42 S. Zhang, S. Tsuzuki, K. Ueno, K. Dokko and M. Watanabe, Angew. Chem., Int. Ed., 2015, 54, 1302.

$43 \mathrm{~J} . \mathrm{Lu}, \mathrm{X}$. Bo, H. Wang and L. Guo, Electrochim. Acta, 2013, 108, 10.

44 R. Liu, D. Wu, X. Feng and K. Mullen, Angew. Chem., Int. Ed., 2010, 49, 2565.

45 Y. C. Zhao, D. L. Yu, H. W. Zhou, Y. J. Tian and O. Yanagisawa, J. Mater. Sci., 2005, 40, 2645.

46 X. Li, J. Liu, Y. Zhang, Y. Li, H. Liu, X. Meng, J. Yang, D. Geng, D. Wang, R. Li and X. Sun, J. Power Sources, 2012, 197, 238. 47 Z. Li, N. Liu, X. Wang, C. Wang, Y. Qi and L. Yin, J. Mater. Chem., 2012, 22, 16640. 